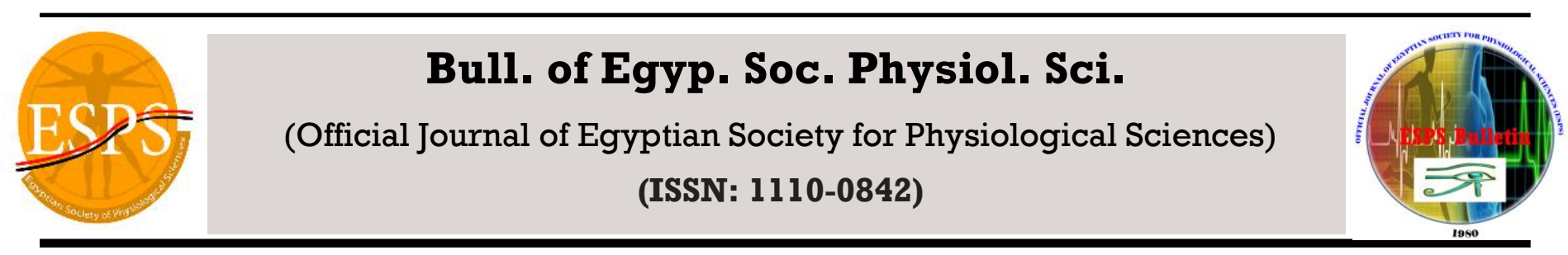

\title{
Role of Berberine in Diabetic Adult Male Rats
}

\author{
Nashwa A Abd El-Mottaleb', Hoda K Abd-Elhady², Khalid M Hassanin³, Ali A Khaleel², Emtethal M \\ Mostafa $^{1}$ \\ Medical Physiology Department, Faculty of Medicine, Assiut University, Egypt1 \\ Physiology Department, Faculty of Medicine, Al-Azhar University (Assiut), Egypt 2 \\ Pathology Department, Faculty of Veterinary Medicine, Assiut University, Egypt 3
}

Received: Aug 13, 2014

Accepted: Oct 14, 2104

Available online: Nov 5, 2014

\section{Keywords}

- Berberine

- Diabetes

- Lipid Profile

- Oxidative Stress

- Kidney functions

- Vagal and

sympathetic nerve activity

\begin{abstract}
Aim: To assess the effect of berberine (BBR) on blood glucose, insulin, lipid profile, oxidative stress and kidney functions in diabetic adult male rats and detect its mechanism(s) of action. Methods: Eighty adult male rats were divided into ten groups. Three experiments were carried out. Experiment I included control group, diabetic control and BBR treated groups (300 $\mathrm{mg} / \mathrm{kg} /$ day) orally for 1, 2, 4 and 6 weeks. The glucose level, insulin, lipid profile, MDA, TAC, urea and creatinine were measured. Samples from pancreas, liver and kidney were histologically examined. Experiment II: BBR effect after pretreatment with $10 \%$ glucose to tongue on vagal nerve activity was recorded. Experiment III: The vagal and sympathetic nerve activity of BBR after administration of atropine, reserpine and propranolol were investigated. Results: Berberine led to significantly decreased glucose level, TC, TG, LDL, MDA, urea and creatinine and significantly increased insulin, HDL and TAC levels after 2 and 4 weeks compared to diabetic control. The histological results confirmed the blood results. Berberine after $10 \%$ glucose on the tongue significantly decreased the rate of vagal nerve activity when compared with control and $10 \%$ glucose alone. Berberine significantly increased the rate of vagal and sympathetic nerve activity but this rate decreased significantly in pre-treated rats with atropine, prazocine and propranolol when compared to berberine level. Conclusion: Berberine may have antidiabetic effect. Berberine may exert its action on glucose level through inhibition of sweet taste receptors. It can act by activation of the cholinergic receptor, $\alpha$ and $\beta$ adrenoceptors.
\end{abstract}

Corresponding author: Nashwa Aly Abd El-Mottaleb, Assistant Professor of Medical Physiology, Medical Physiology Department, Faculty of Medicine, Assiut University, Egypt 


\section{INTROUCTION}

Diabetes mellitus is a growing public health affecting people worldwide both in developing and developed countries, and possess a major socio-economic challenge (1). It is also a complex disorder with profound consequences both acute and chronic. Genetic and environmental factors play a role in the development of the disease (2). Type 1 diabetes mellitus is characterized by loss of the insulin-producing beta cells of the islets of Langerhans in the pancreas, leading to insulin deficiency. This type can be further classified as immune-mediated or idiopathic. The majority of type 1 diabetes is of the immune-mediated nature, in which beta cell loss is a T-cell-mediated autoimmune attack (3).The use of natural products for the treatment of metabolic diseases has not been explored in depth despite the fact that a number of modern oral hypoglycemic agents such as metformin are derivatives of natural plant products (4).

Berberine is a natural isoquinoline alkaloid isolated from the Chinese herb Rhizoma coptidis, which has been widely used in Chinese herbal medicine. Berberine has gained much attention in recent years owing to its multiple biochemical and pharmacological effects, including anticancer, antiviral, and antibacterial activities (5). It was found by accident that berberine had effect on the decrease of blood glucose when the authors used berberine to treat diarrhea in patient who suffer from diabetes (6).

Berberine (BBR) is demonstrated to have hypoglycemic effect in vitro and in vivo. It also has anti-obesity and anti-dyslipidemia activities
(7). A large number of clinical trials and animal experiments about berberine improving insulin resistance and lowering hyperglycemia were reported. However, the underlying mechanisms remain uncertain (8). Thus, this study aims to assess the effect of BBR on blood glucose, insulin, lipid profile, oxidative stress and kidney functions in diabetic adult male rats. Also, evaluate the possible interaction between BBR and sweet taste receptors and the relationship between BBR and neural control of blood glucose concentration in attempt to detect its mechanism(s) of action.

\section{MATERIALS AND METHODS}

\section{Experimental animals:}

The present study was carried out on eighty adult male albino rats weighing 220 to $250 \mathrm{~g}$. Rats were brought from animal house, Faculty of Medicine, Assiut University, Assiut, Egypt, and were maintained on a balanced diet with water supply freely in clean containers. The experimental procedures were carried out according to "Guidelines of Experiments on Animals" at Faculty of Medicine, Assiut University, Egypt.

\section{Chemicals and kits}

Streptozotocin (STZ) was purchased from MP Biomedicals, France. Berberine chloride hydrate and Propranolol ( $\beta$-adrenoreceptor blocker) were purchased from Alfa Aesar, Germany. Urethane was purchased from Aldrich chemical company, Inc. Wis., USA. Atropine sulfate was purchased from Sigma Chemical Company, St., Lousis, MO, USA. Prazocin ( $\alpha$ - 
adrenoreceptor blocker) was purchased from Sigma-Aldrich, Germany.

Blood glucose, serum total cholesterol (TC), serum triglycerides (TG), serum high density lipoprotein (HDL) and blood urea kits were purchased from Egyptian company for biotechnology, Egypt. Insulin kit was purchased from Immunospec Corporation, Canoga Park, CA. Serum malonaldhyde (MDA) and total antioxidant capacity (TAC) kits were purchased from Biodiagnostic Company, Egypt. Serum creatinine kit was purchased from BIOLABO SA, France.

\section{Induction of diabetes:}

Diabetes was induced in rats by single intrapertonial injection of freshly streptozotocin 50 $\mathrm{mg} / \mathrm{kg}$ body weight (9). The animals were fasted for overnight 12 hours before STZ injection. After injection, the rats were kept for next 48 hours on oral $10 \%$ glucose solution on top of their chaw. Administration of glucose is to prevent hypoglycemia as STZ is capable of producing fatal hypoglycemia due to destruction of $\beta$ cells which in turn results in to massive pancreatic insulin release (10).

After 3 days, diabetes was confirmed by glucometer (Bionime, Taiwan). The rats with fasting blood glucose level over $250 \mathrm{mg} / \mathrm{dl}$ were considered diabetic and selected for use (11).

\section{Experimental design:}

\section{Experiment I:}

This experiment was designed to assess the effect of berberine on blood glucose, insulin, lipid profile, oxidative stress and kidney functions in diabetic adult male rats. In this experiment, 6 groups (8 animals each) were used.

Group (1) consisted of 8 rats and served as control group. They received distilled water orally. They were sacrificed at the end of the six weeks.

Group (2) consisted of 8 diabetic rats and served as diabetic control group. They received distilled water orally. They were sacrificed at the end of the six weeks.

Groups (3-6) consisted of 8 diabetic rats were treated with BBR dissolved in boiling water (300 $\mathrm{mg} / \mathrm{kg} /$ day) orally (12) for 1, 2, 4 and 6 week.

\section{Biochemical estimations:}

The levels of glucose, insulin, total cholesterol (TC), triacylglycerols (TAG), highdensity lipoprotein-cholesterol (HDL-C), malonaldhyde (MDA), total antioxidants capacity (TAC), blood urea and serum creatinine were measured using enzymatic colorimetric assay kits, while low-density lipoprotein-cholesterol (LDL) using Friedewald's formula (13):- LDL in $\mathrm{mg} / \mathrm{dl}=$ TC- (HDL -TG/5) was calculated.

\section{Experiment II:}

This experiment was designed to elicit the possible interaction between BBR and sweet taste receptors. One group of rats (Group 7, consisted of 8 animals) was used.

\section{Experimental protocol:}

The rats were prepared for recording of vagal nerve activity. Following surgical preparation, the animals allowed to reach steady state conditions which was achieved within $15 \mathrm{~min}$ 
then a baseline period (control) was performed. $10 \%$ glucose solution was applied on the tongue with a syringe for 5 minutes and the tongue was flushed away with distilled water at the end of taste stimulation (14). A rest period of $30 \mathrm{~min}$ was achieved then the same animals received BBR $(300 \mathrm{mg} / \mathrm{kg} /$ day) orally after application of $10 \%$ glucose solution on the tongue which flushed away with distilled water 5 minutes later.

\section{Operative procedure}

Rats were anaesthetized with ip injection of urethane $(600 \mathrm{mg} / \mathrm{kg})(15)$.

\section{Preparation of the vagus nerve (16)}

To expose the right vagus nerve, make a midline incision in the full length of the neck. This will expose the trachea and underneath it the esophagus. Alongside these structures run the carotid arteries with the vagus nerves. Locate the right carotid artery and vagus nerve but do not attempt to separate the two, since this might damage the nerve. The vagus nerve removed from the trunk by making a longitudinal cut through the sheath and then gently lifting or rolling the nerve out of the sheath. It was unnecessary to separate the vagal trunk from the common carotid artery.

\section{Experiment III:}

The purpose of this experiment was to evaluate the relationship between BBR and neural control of blood glucose concentration through efferent vagal (parasympathetic) and sciatic nerve (sympathetic) activity to the pancreas. In this experiment 3 groups (Groups 8, 9 and 10), 8 animals each were used.

\section{Experimental protocol:}

Group (8): All rats of this group were prepared for recording of efferent vagal (parasympathetic) nerve activity. When the steady state was reached, a baseline period (control) was performed. Animals received berberine (300 mg/kg/day) orally. After reaching the baseline, the same animals received BBR (300 mg/kg/day) orally following previous administration of atropine $(1 \mathrm{mg} / \mathrm{kg}$, i.v) (17) as a cholinergic receptor blocker.

Group (9): All rats of this group were prepared for recording of efferent sciatic (sympathetic) nerve activity. When the steady state was reached, a baseline period (control) was performed. The animals received BBR (300 mg/kg/day) orally. After reaching the baseline, the same animals received $\mathrm{BBR}(300 \mathrm{mg} / \mathrm{kg} /$ day) orally following previous administration of prazocin $(3 \mathrm{mg} / \mathrm{kg}$, i.p) (18) as an $\alpha$-adrenergic receptor blocker.

Group (10): All rats of this group were prepared for recording of efferent sciatic (sympathetic) nerve activity. When the steady state was reached, a baseline period (control) was performed. The animals received BBR (300 mg/kg/day) orally. After reaching the baseline, the same animals received BBR (300 mg/kg/day) orally following previous administration of propranolol $(1 \mathrm{mg} / \mathrm{kg}$, s.c) (18) as a $\beta$-adrenergic receptor blocker.

\section{Operative procedure}

Rats were anaesthetized with ip injection of urethane $(600 \mathrm{mg} / \mathrm{kg})(15)$. 


\section{Preparation of the vagus nerve (16)}

The vagus nerve was prepared as mentioned previously.

\section{Preparation of the sciatic nerve (19)}

The rump and the whole of the right leg are shaved. The skin from the protuberance of the ischial tuberosity on the buttock is cut with sharp scissors almost to the back of the ankle, so as to obtain access to the popliteal space. This opened with the fingers to expose the sciatic nerve. Which is seen as a large trunk dividing into the medial and lateral popliteal nerves and protected with cotton and soaked in liquid paraffin.

\section{Nerve recording}

The vagal and sciatic nerve traffics were recorded after their stimulation with microelectrode connected to the stimulator cable (electronic stimulator). Set the stimulator frequency at $25 / \mathrm{sec}$, the duration to $2 \mathrm{~m} \mathrm{sec}$ and the strength to $3-5$ volts. The vagal and sciatic signals were magnified with Washington coupler. The nerve responses were recorded on the physiograph. The rate was expressed as burst $/ \mathrm{min}$.

\section{Collection of blood samples:}

After 12 hours over night fasting, morning blood samples were collected from retro-orbital venous plexus before scarification. The blood was collected into a dry clean graduated glass centrifuge tube and serum was separated by centrifugation at 5000 r.p.m for 10 minutes. The separated serum was aliquotted and stored frozen in Eppindorffs tube at -20c until use.
After scarifying animals, the pancreas, liver and kidney were taken for histopathology.

\section{Statistical analysis}

Statistical analysis was done using the computer program (SPSS). The quantitative data were presented in the form of mean \pm standard error (S.E). Statistical analysis of the difference between groups was performed by using One-way analysis of variance (ANOVA) followed by Tukey-Kramer test for differences between means. A value of $\mathrm{P}<0.05$ were used as the limit for statistical significance.

\section{RESULTS}

\section{Experiment I:}

Table (1) summarizes the effect of berberine on biochemical parameters in adult male diabetic rats. Intrapertonial injection of STZ $(50 \mathrm{mg} / \mathrm{kg}$ BW) to diabetic control rats caused a significant increase in fasting blood glucose, TC, TG and LDL, MDA, blood urea and serum creatinine levels and significant decrease in serum insulin, HDL and TAC levels in comparison with the control level. Berberine decreases the blood glucose, TC, TG and LDL, MDA, blood urea and serum creatinine levels and increases insulin, HDL and TAC levels in comparison to diabetic control. The effect appeared at 2 weeks and approached the control level on the 4 weeks. There were significant increased levels of glucose, TC, TG, LDL, MDA, blood urea and serum creatinine and significant decreased levels of insulin, HDL and TAC after administration of berberine for 6 weeks when compared with normal control. 


\section{Histopathological examination:}

The histopathological examination of HEstained sections of the pancreas of normal control rats showed normal appearance of the pancreas. The acinar cells are arranged in lobules with prominent nuclei. The islet cells are seen embedded within the acinar cells and surrounded by a fine capsule (Fig. 1 A). The pancreas of diabetic control rats showed vascular and parenchymal changes. The vascular changes were in the form of hemorrhage, congestion, and edema (Fig. 1 B).

Table (1): Effect of berberine on biochemical parameters in adult male diabetic rats

\begin{tabular}{|c|c|c|c|c|c|c|}
\hline & \multirow[b]{2}{*}{ Control } & \multirow{2}{*}{$\begin{array}{l}\text { Diabetic } \\
\text { control }\end{array}$} & \multicolumn{4}{|c|}{ BBR treated } \\
\hline & & & $1^{\text {st }}$ week & $2^{\text {nd }}$ week & $4^{\text {th }}$ week & $6^{\text {th }}$ week \\
\hline Glucose $(\mathrm{mg} / \mathrm{dl})$ & $80.6 \pm 2.1$ & $255.0 \pm 3.5$ & $253.0 \pm 3.5$ & $\begin{array}{c}190.8 \pm 4.1 \\
\mathrm{a}^{* * * *} \\
\mathrm{~b}^{* * *}\end{array}$ & $\begin{array}{c}85.7 \pm 1.9 \\
b^{* *}\end{array}$ & $\begin{array}{c}107.0 \pm 1.4 \\
\mathrm{a}^{* *} \\
\mathrm{~b}^{* *}\end{array}$ \\
\hline Insulin (mg/dl) & $3.7 \pm 0.7$ & $1.3 \pm 0.2$ & $1.4 \pm 0.2$ & $\begin{array}{c}2.4 \pm 0.3 \\
a^{* * *} \\
b^{* *}\end{array}$ & $\begin{array}{c}3.5 \pm 0.9 \\
\mathrm{~b}^{* * * *}\end{array}$ & $2.8 \pm 0.2$ \\
\hline TC (mg/dl) & $99.1 \pm 2.2$ & $199 \pm 1.9$ & $198.4 \pm 2.2$ & $\begin{array}{c}177.6 \pm 2.4 \\
\mathrm{a}^{* * *} \\
\mathrm{~b}^{*}\end{array}$ & $\begin{array}{c}105.6 \pm 2.2 \\
b^{* *}\end{array}$ & $\begin{array}{c}120.5 \pm 0.3 \\
a^{*} \\
b^{* *}\end{array}$ \\
\hline TG (mg/dl) & $71.5 \pm 1.6$ & $167.6 \pm 3.0$ & $165.5 \pm 1.4$ & $\begin{array}{c}146.7 \pm 3.9 \\
a^{* * * *} \\
b^{*}\end{array}$ & $\begin{array}{c}76.7 \pm 2.0 \\
\mathrm{~b}^{* *}\end{array}$ & $\begin{array}{c}85.5 \pm 2.7 \\
\mathrm{a}^{*} \\
\mathrm{~b}^{* *}\end{array}$ \\
\hline HDL (mg/dl) & $95.6 \pm 1.3$ & $56.9 \pm 1.7$ & $61.9 \pm 2.6$ & $\underset{\substack{\mathrm{a}^{* *} \\
\mathrm{~b}^{* * *}}}{73.9 \pm 1.9}$ & $\begin{array}{c}92.3 \pm 2.1 \\
b^{* * * *}\end{array}$ & $\begin{array}{c}81.5 \pm 1.9 \\
\mathrm{a}^{*} \\
\mathrm{~b}^{* * * *}\end{array}$ \\
\hline LDL (mg/dl) & $99.8 \pm 1.4$ & $\underset{a^{* * * *}}{172.6} \pm 6.7$ & $166.1 \pm 1.7$ & $\underset{\substack{\mathrm{a}^{* * * *} \\
\mathrm{~b}^{*}}}{149.1 \pm 7.3}$ & $\begin{array}{c}102.1 \pm 2.6 \\
b^{* *}\end{array}$ & $\underset{\substack{\mathrm{a}^{*} \\
\mathrm{~b}^{* * *}}}{115.6} \mathbf{2 . 8}$ \\
\hline MDA $(\mathrm{mg} / \mathrm{dl})$ & $1.9 \pm 0.08$ & $4.8 \pm 0.4$ & $4.5 \pm 0.4$ & $\begin{array}{l}3.4 \pm 0.3 \\
a^{* * * * *} \\
b^{* * *}\end{array}$ & $\begin{array}{c}2.0 \pm 0.1 \\
b^{* *}\end{array}$ & $\begin{array}{c}2.8 \pm 0.3 \\
a^{* * *} \\
b^{* * *}\end{array}$ \\
\hline TAC (mmol/L) & $334.3 \pm 7.4$ & $237 \underset{a^{* *}}{ \pm * 8.1}$ & $243.1 \pm 6.2$ & $\begin{array}{c}267.1 \pm 4.8 \\
a^{* * *} \\
b^{*}\end{array}$ & $\begin{array}{c}330.6 \pm 6.3 \\
b^{* * *}\end{array}$ & $\begin{array}{c}303.8 \pm 4.8 \\
\substack{a^{*} \\
b^{* * *}}\end{array}$ \\
\hline Urea $(\mathrm{mg} / \mathrm{dl})$ & $41.1 \pm 1.6$ & $\underset{a^{* * * *}}{205.1}$ & $201.0 \pm 2.8$ & $\underset{\substack{\mathrm{a}^{* * * *} \\
\mathrm{~b}^{*}}}{148.9 \pm 2.8}$ & $\begin{array}{c}43.5 \pm 0.9 \\
b^{* * *}\end{array}$ & $\begin{array}{c}55.0 \pm 2.5 \\
\mathrm{a}^{*} \\
\mathrm{~b}^{* * *}\end{array}$ \\
\hline Creatinine $(\mathrm{mg} / \mathrm{dl})$ & $0.8 \pm 0.04$ & $2.1 \pm 0.1$ & $1.9 \pm 0.3$ & $\begin{array}{c}1.3 \underset{\mathrm{a}^{* *}}{ \pm 0.03} \\
\mathrm{~b}^{* * *}\end{array}$ & $\begin{array}{c}0.87 \pm 0.05 \\
b^{* *}\end{array}$ & $\begin{array}{c}1.1 \pm 0.06 \\
a^{* *} \\
b^{* *}\end{array}$ \\
\hline
\end{tabular}

Data are the mean \pm SD for eight animals in each group. a $=$ p-value $(*=<0.05 ; * *=<0.01$; and $* * *=<0.001)$ : all groups vs. control; $\mathrm{b}=\mathrm{p}$-value $(*=<0.05 ; * *=<0.01$; and $* * *=<0.001)$ : all groups vs. diabetic control. Unlabelled comparisons are non-significant. BBR: Berberine $(300 \mathrm{mg} / \mathrm{kg}$, orally). TC: total cholesterol, TG: triglycerides, HDL: high-density lipoprotein-cholesterol, LDL: low-density lipoprotein cholesterol, MDA: malonaldhyde and TAC: total antioxidant capacity. 

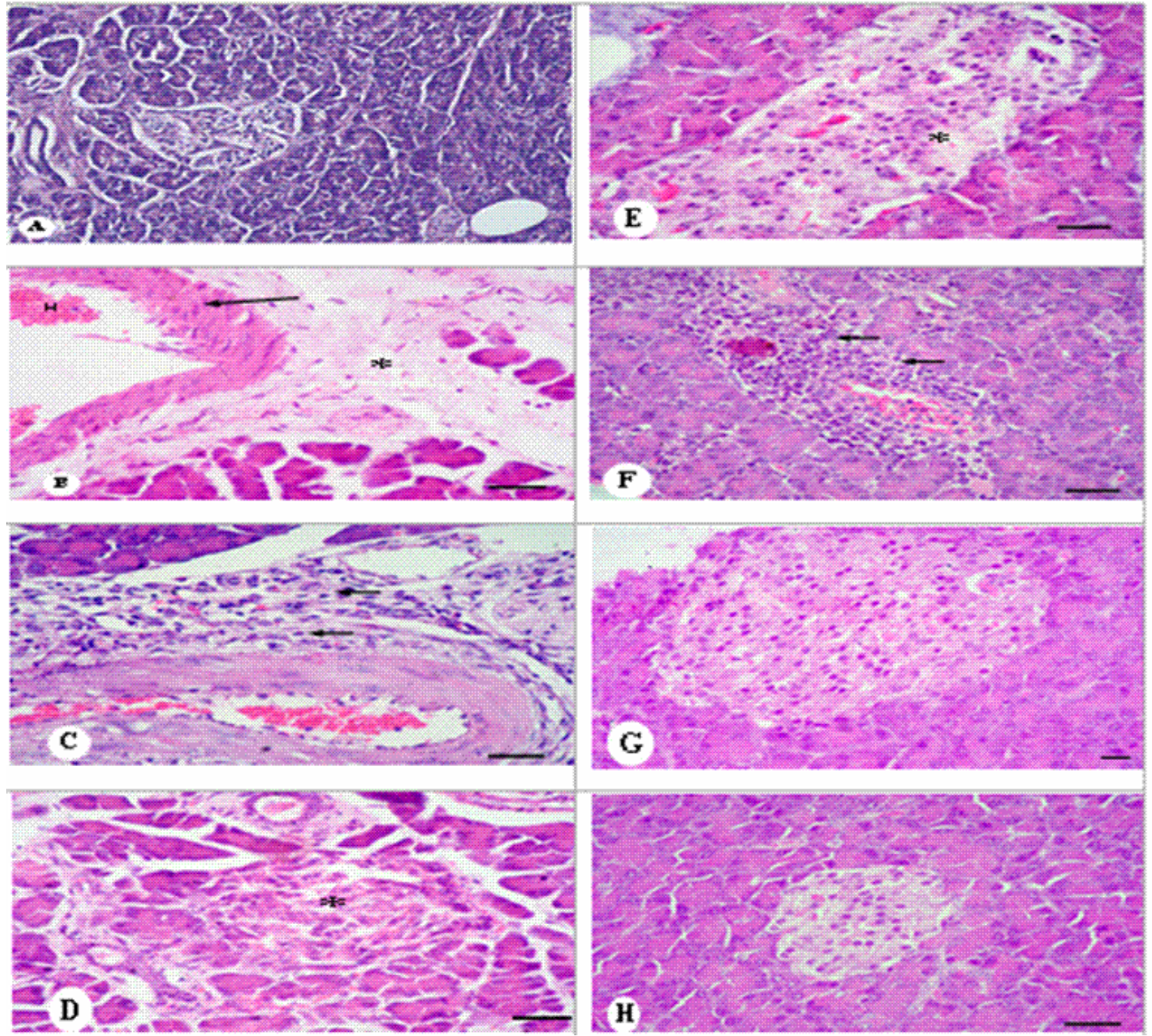

Fig 1: Representative micrograph of rat's pancreas. A) Normal control rats showed normal appearance of pancreas. B) Diabetic control rats showed hemorrhage $(\mathrm{H})$, congestion of the blood vessel (arrow) and edema of the interstitium (asterisk), C) Fibrosis in the interstitium and mononuclear infiltration (arrows) and D) Degeneration of islet cells (asterisk). E) and F) Berberine treated rats for 1 and 2 weeks showed pancreas with degeneration of the islet (asterisk) and mononulear infiltration (arrows). G) Berberine treated rats for 4 weeks showed normal appearance. H) Berberine treated rats for 6 weeks showed pancreas with degeneration of the islet, HE stain. Bar $=50 \mu \mathrm{m}$.

Fibrosis in the interstitium and infiltration of mononuclear cells such as lymphocytes were seen (Fig. $1 \mathrm{C}$ ). The parenchymal changes were observed in the islet of Langerhan's in the form of degeneration (Fig. $1 \mathrm{D}$ ). The pancreas of berberine treated rats for one and two weeks revealed degeneration of the islet of Langerhan's and heavy infiltration of lymphocytes around the blood vessels (Fig. $1 \mathrm{E}$ and F). Pancreas of berberine treated rats for 4 weeks revealed normal appearance (Fig. $1 \mathrm{G}$ ). The pancreas of berberine treated rats for six weeks revealed degeneration of the islet of Langerhan's (Fig. $1 \mathrm{H}$ ).

Examination of the Liver of a control rats showed that it is composed of hexagonadal or pentagonadal lobules with central veins and peripheral hepatic triads or tetrads embedded in connective tissue. Hepatocytes are arranged in trabecules running radiantly from the central vein and 
are separated by sinusoids containing Kupffer cells. They are regular and contain a large spheroidal nucleus with a distinctly marked nucleolus and peripheral chromatin distribution. Some cells have two nuclei (Fig.2 A). The liver of diabetic control rats revealed glycogen depletion in the hepatocytes, pyknosis of the nucleus and focal hemorrhages in some areas (Fig.2 B).

The liver of rats examined after one and two weeks of berberine treatment showed focal necrosis of the hepatocytes associated with mononuclear infiltration. In addition, the portal area showed congestion of the portal blood vessels with heavy infiltration of mononuclear cells (Fig. $2 \mathrm{C}$ and D). Liver of berberine treated rats for 4 weeks revealed normal appearance (Fig. E). The liver of berberine treated rats for six weeks showed focal necrosis of the hepatocytes associated with mononuclear infiltration. In addition, the hepatocytes showed depletion of the glycogen (Fig. 2 F)
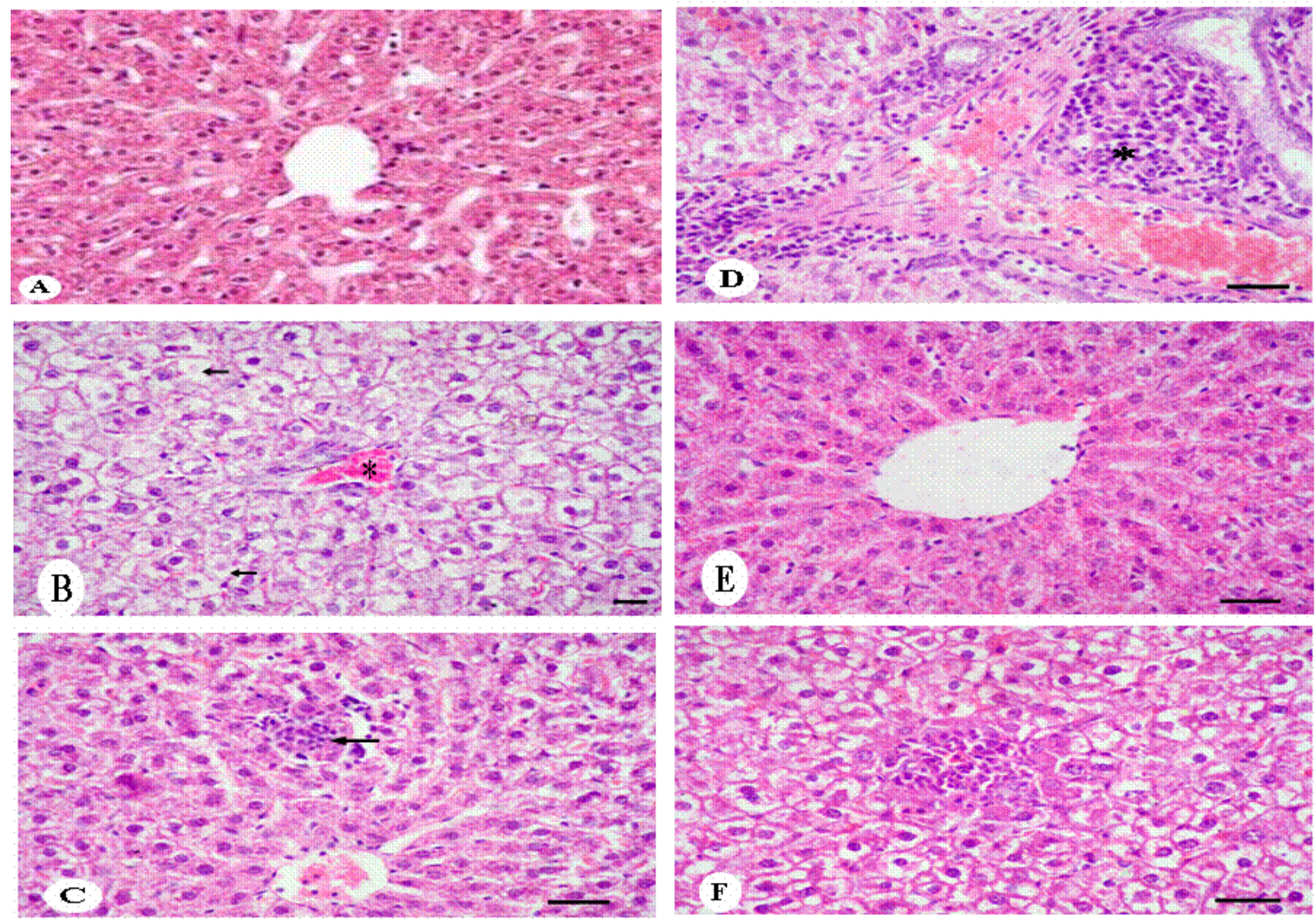

Fig 2: Representative micrograph of rat's liver. A) Normal control rats showed normal appearance of liver. B) Diabetic control rats showed glycogen depletion from the Hepatocytes (arrows) and focal hemorrhagic area (asterisk). C) and D) Berberine treated rats for 1 and 2 weeks showed Liver with focal area of necrosis (arrow) and infiltration of mononuclear cells in the portal area (asterisk). E) Berberine treated rats for 4 weeks showed normal appearance. F) Berberine treated rats for 6 weeks showed glycogen depletion and focal area of mononuclear cells HE stain. Bar $=50 \mu \mathrm{m}$.

The kidney of the control rats showed normal renal tissue. The glomeruli were lined with flattened endothelial cells and Bowman's space was clear. The vasculature was normal and the renal tubules were lined with cuboidal epithelium (Fig. 3 A). The kidney of diabetic rats revealed vascular and parenchymal changes. The vascular changes were in the form glomerular swelling due to congestion and congestion of the blood vessels (Fig. 3 B). 
Proliferation of the mesangial cells was also seen (Fig. 3 C). Renal tubules showed vacuolar degeneration was seen (Fig. 3 D). Heavy infiltrations with lymphocytes were noticed in the interstitium (Fig. 3 E). The kidney of berberine treated rats for one and two weeks revealed glomerular swelling due to proliferation of the mesangial cells and vacuolar degeneration of the renal tubules was seen (Figs. $3 \mathrm{~F}$ and $\mathrm{G}$ ). The kidney
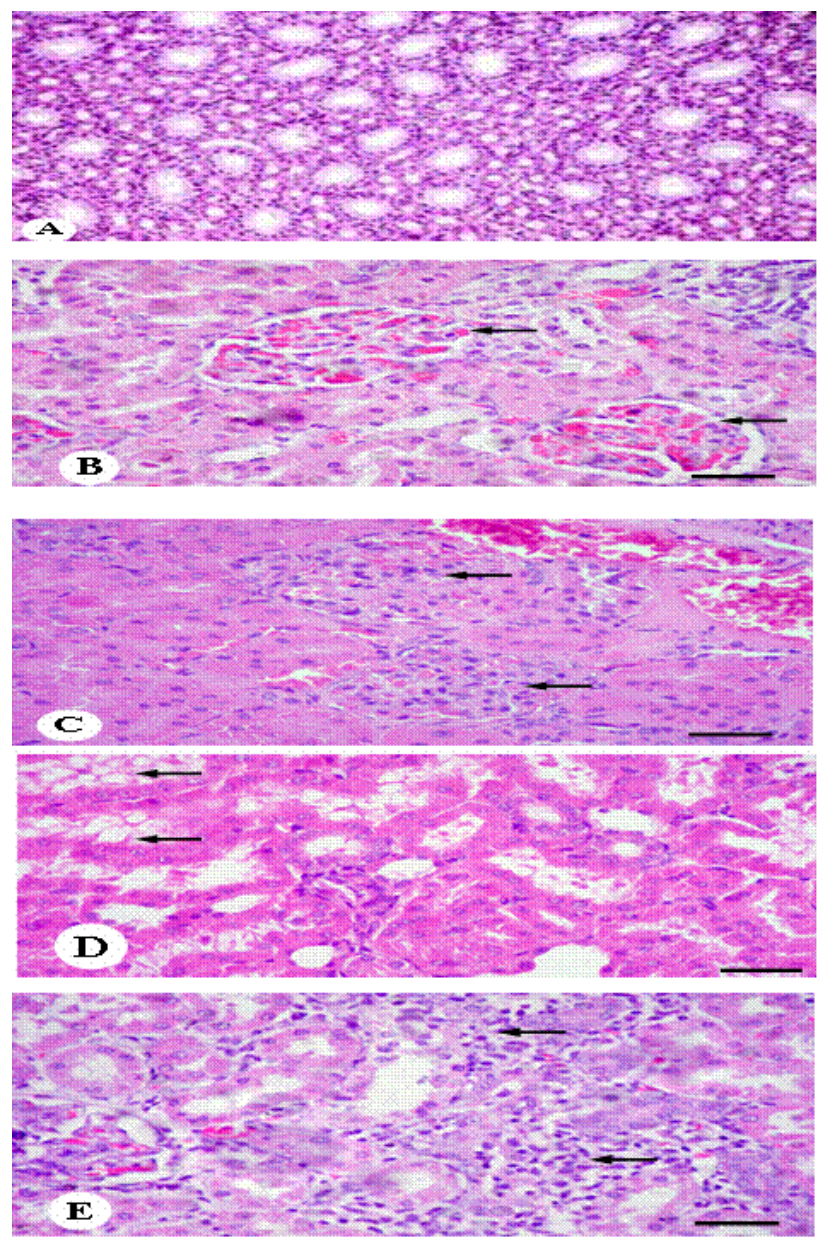

of berberine treated rats for 4 weeks revealed normal appearance (Fig. $3 \mathrm{H}$ ). The kidney of berberine treated rats for six weeks revealed glomerular swelling due to both congestion of the glomerulous and proliferation of the mesangial cells. The interstitial tissue were infiltrated with mononuclear cells especially lymphocytes (Fig. 3 I and J).
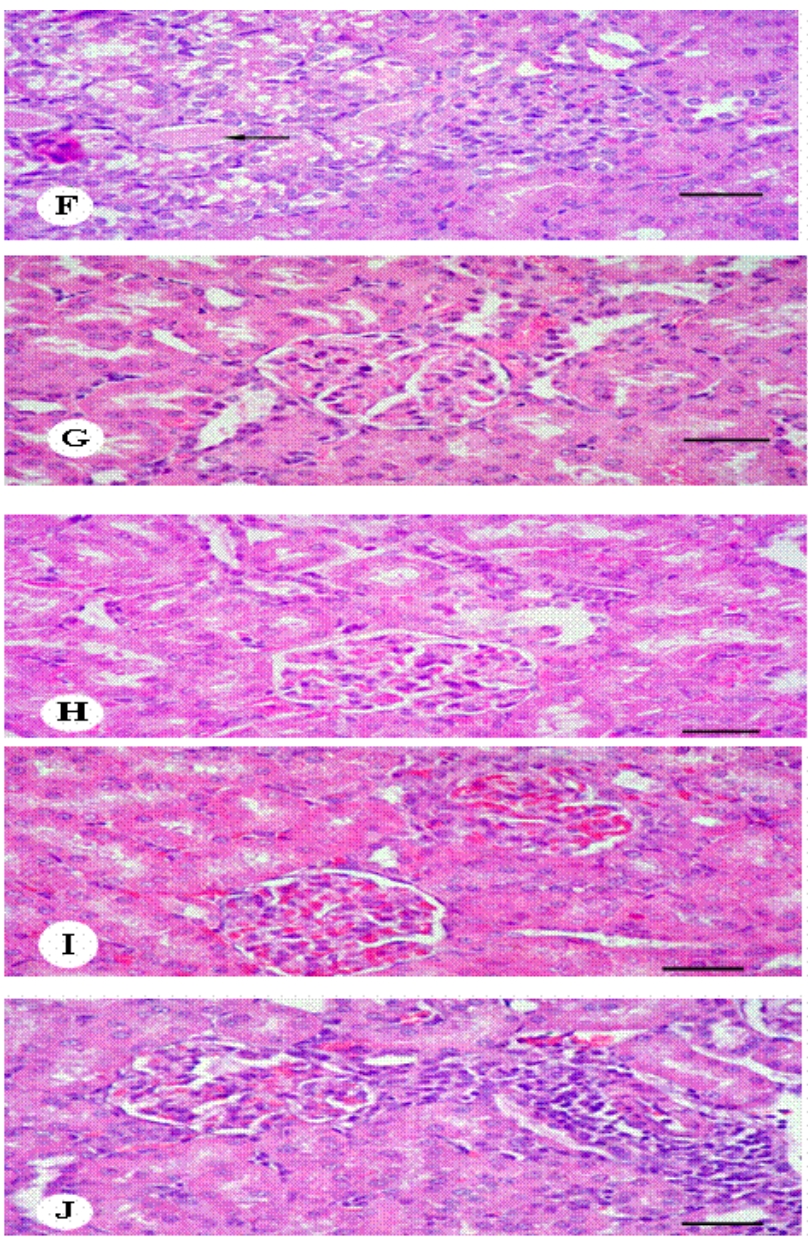

Fig 3: Representative micrograph of rat's kidney. A) Normal control rats showed normal appearance of kidney. B) Diabetic control rats showed glomerular swelling (arrows), C) Proliferation of mesangial cells (arrows), D) Vacuolar degeneration of the renal tubular epithelium (arrows) and E) Mononuclear infiltration (arrows). F) and G) Berberine treated rats for 1 and 2 weeks showed vacuolar degeneration (arrow) and proliferation of the mesangial cell (asterisk). H) Berberine treated rats for 4 weeks showed normal appearance of the kidney. I) and J) Berberine treated rats for 6 weeks showed kidney with glomerular swelling and mononuclear infiltration in the interstitium. HE stain. Bar $=50 \mu \mathrm{m}$.

\section{Experiment II:}

Application of $10 \%$ glucose to the tongue of rats of group (7) showed significant increase in the mean levels of the rate of vagal nerve activity compared with control level $(23.0 \pm 0.5$ vs $8.6 \pm$ 
0.4 bursts/min, $\mathrm{P}<0.001)$.

Oral BBR administration (300 $\mathrm{mg} / \mathrm{kg})$ after $10 \%$ glucose to the tongue decreased

significantly the mean level of the rate of vagal nerve activity when compared with that of the control $(3.9 \pm 0.5$ vs $8.6 \pm 0.4$ bursts $/ \mathrm{min}, \mathrm{P}<0.01)$ and when compared with that of the $10 \%$ glucose (3.9 \pm 0.5 vs $23.0 \pm 0.5$ bursts $/ \mathrm{min}, \mathrm{P}<0.01)$ (Fig 4 A, B).
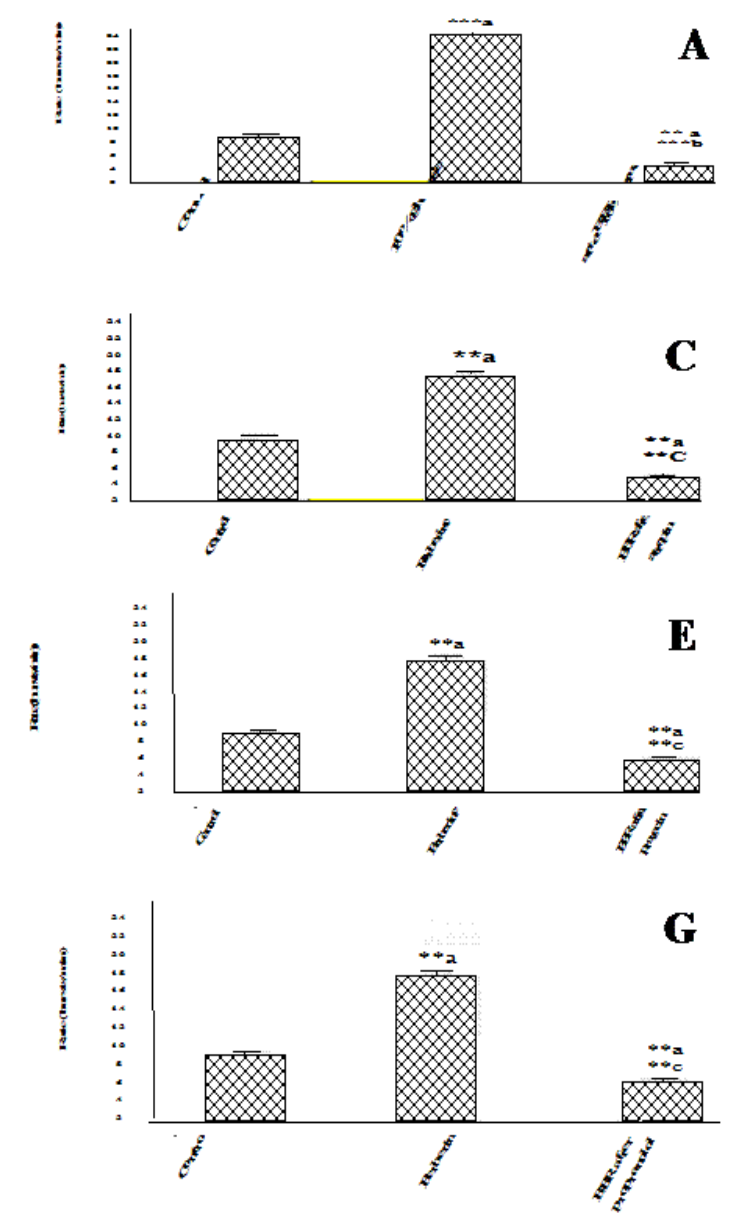

$\mathbf{A}$

\section{Experiment III:}

Berberine treatment ( $300 \mathrm{mg} / \mathrm{kg} /$ orally) in group (8) showed a significant increase in the mean level of the rate of vagal nerve activity when compared with that of the control level $(17.4 \pm 0.3$ vs $9.1 \pm 0.3$ bursts $/ \mathrm{min}, \mathrm{P}<0.01)$. In pretreated rats with atropine, BBR caused a significant decrease in the mean level of the rate of vagal nerve activity compared to the control level $(4.1 \pm 0.3$ vs $9.1 \pm 0$. 3 bursts/min, $\mathrm{P}<0.01)$ and BBR alone $(4.1 \pm 0.3$ vs $17.4 \pm 0.3$ bursts/min, $\mathrm{P}<0.01)($ Fig $4 \mathrm{C}, \mathrm{D})$.

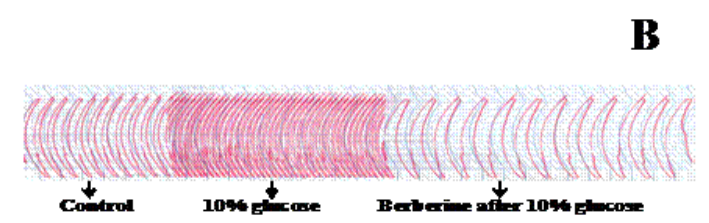

D
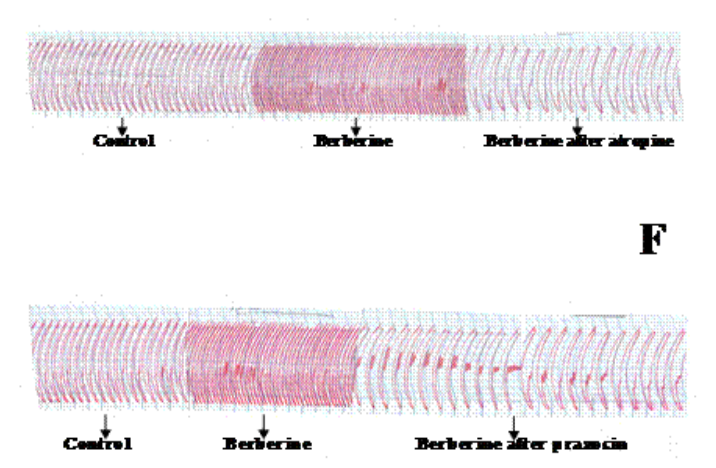

H

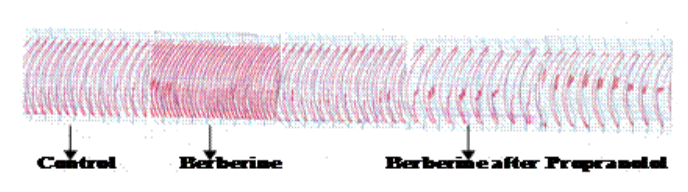

Fig 4: Graphic representation and recording of the of vagal activity of oral berberine $(300 \mathrm{mg} / \mathrm{kg})$ in adult male rats after pretreatment with $10 \%$ glucose to the tongue (A, B), pretreatment with cholinergic receptor blocker (atropine) (C, D). Graphic representation and recording of sympathetic nerve activity of oral berberine in adult male rats after pretreatment with $\alpha$ adrenergic receptor blocker (prazocin) (E, F) and $\beta$ adrenergic receptor blocker (propranolol) $(\mathrm{G}, \mathrm{H})$. $\mathrm{a}=\mathrm{p}$-value $(* *=<0.01$; and $* * *=<0.001)$ : versus control; $\mathrm{b}=\mathrm{p}$-value $(* * *=<0.001)$ : versus $10 \%$ glucose; $\mathrm{c}=\mathrm{p}$-value $(* *=$ $<0.01)$ versus berberine 
Berberine treatment ( $300 \mathrm{mg} / \mathrm{kg} /$ orally) in group (9) showed a significant increase in the mean level of the rate of sympathetic nerve activity when compared with the control level $(17.5 \pm 0.3$ vs $9.3 \pm 0.4$ bursts/min, $\mathrm{P}<0.01)$. In pretreated rats with prazocin, BBR caused a significant decrease in the mean level of the rate of sympathetic nerve activity compared to the control level $(5.1 \pm 0.3$ vs $9.0 \pm 0.4$ bursts $/ \mathrm{min}, \mathrm{P}<0.01)$ and $\mathrm{BBR}$ alone $(5.1 \pm 0.3$ vs $17.1 \pm 0.3$ bursts/min, $\mathrm{P}<0.01)$ (Fig 4 E, F).

Berberine treatment in $(300 \mathrm{mg} / \mathrm{kg} /$ orally $)$ in group (10) showed a significant increase in the mean level of the rate of sympathetic nerve activity when compared with that of the control level $(17.1 \pm 0.3$ vs $9.0 \pm 0.4$ bursts/min, $\mathrm{P}<0.01)$. In pretreated rats with propranolol, BBR caused a significant decrease in the mean level of the rate of sympathetic nerve activity compared to the control level $(4.8 \pm 0.3$ vs $9.0 \pm 0.4$ bursts $/ \mathrm{min}, \mathrm{P}<0.01)$ and BBR alone $(4.8 \pm 0.3$ vs $17.1 \pm 0.3$ bursts $/ \mathrm{min}$, $\mathrm{P}<0.01$ ) (Fig $4 \mathrm{G}, \mathrm{H}$ ).

\section{DISCUSSION}

\section{Glucose and insulin}

In the present study, intrapertonial injection of STZ $(50 \mathrm{mg} / \mathrm{kg} \mathrm{BW})$ to diabetic control rats caused a significant increase in fasting blood glucose level and significant decrease in serum insulin level in comparison with the control level. The histopathological examination of the pancreas of diabetic rats showed vascular and parenchymal changes. In accordance with the present results, Riad et al. (20) showed that streptozotocin-induced diabetic rats had low production of insulin and high levels of blood circulating glucose. Changes in blood glucose and insulin levels reflect abnormalities in $\beta$ cells function or structure. Also, Fukudome et al. (21) reported that streptozotocin generates reactive oxygen species, which contribute to DNA fragmentation and evoke other deleterious changes in $\beta$ cells.

$$
\text { In the present study, the }
$$
administration of BBR to diabetic rats decreases the blood glucose level and increases insulin level in comparison to diabetic control. The effect appeared at 2 weeks and approached the control level on the 4 weeks. The histopathological examination of the pancreas of BBR treated rats for 4 weeks showed normal appearance. Our results are in the same line with other results obtained by other investigators as; Ko et al. (22) suggested that treatment with BBR prevented the insulin expression and $\beta$ cells number to decrease, and improved them to near the control level. The findings suggest that BBR may regenerate $\beta$ cells and has protective effect on $\beta$ cells from glucose toxicity through insulin secretion from the remnant $\beta$ cells and insulin sensitivity. Also, Zhou et al. (23) added that treatment with BBR took the increased blood glucose in diabetic rats back to the control. Berberine regulated insulin secretion partly through the cAMP signaling pathway. Moreover, Xia et al. (24) showed that BBR may reduce fasting blood glucose through an insulin-independent signaling pathway, such as adenosine 
monophosphate activated protein kinase (AMPK) activation, insulin receptor expression and inhibit mitochondrial production of ATP. AMPK regulates several intracellular systems, including the cellular uptake of glucose, the beta-oxidation of fatty acids, and the biogenesis of GLUT4 (25).

However, Chen et al. (26) suggested that BBR does not increase insulin release and synthesis. Also, Zhou et al. (27) showed that BBR partially inhibits insulin release from $\beta$-cells and directly counteracts glucolipotoxicity In addition to its effects on peripheral metabolism, BBR also exerts direct actions on $\beta$-cells. Moreover, Al-masri et al. (28) reported that berberine inhibited dipeptidyl peptidase-IV which degrades glucagons like peptide-1 (GLP-1). GLP-1 plays a critical role in insulin secretion and signaling (29).

\section{Lipid Profile}

Diabetes mellitus is one of the most common chronic diseases that are associated with dyslipidemia. Diabetic dyslipidemia refers to the combination of abnormalities of plasma lipids and lipoprotein concentrations namely elevated blood levels of TG, LDL and low levels of HDL (30).

The current study showed significant increase in the level of TC, TG and LDL and significant decrease in the level of HDL in STZ-induced rats when compared with normal control and the histological examination of the diabetic rat's liver revealed glycogen depletion in the hepatocytes, pyknosis of the nucleus and focal hemorrhages in some areas. This is in accordance with Zhou et al. (23) who showed that TC, TG and LDL levels of diabetic rats were significantly higher than those of the control ones, while HDL was remarkably lower than those of the control ones. Also, Wasan et al. (31) reported that diabetes increases TC, LDL, and TG as well as decreases HDL concentrations. The mechanism is possibly due to reduction in lipoprotein lipase activity secondary to reduced plasma insulin levels. The present study showed that administration of berberine to diabetic rats decreases serum $\mathrm{TC}$, TG and LDL levels and increase HDL level in comparison to diabetic control. The effect appeared at 2 weeks and approached the control level on the 4 weeks. Our histological results confirm the blood results. In accordance, Zhou et al. (23) found that BBR restored the increased blood glucose, TC, TG, LDL and the decreased HDL levels in diabetic rats to near the control ones. Berberine alleviated the pathological progression of liver and reverted the increased hepatic glycogen and $\mathrm{TG}$ to near the control levels. Also, Li et al. (32) reported that $\mathrm{BBR}$ reduces $\mathrm{LDL}$ by up regulating $\mathrm{LDL}$ receptor mRNA expression post transcriptionally. Moreover, Cao et al. (33) suggested that the TG-lowering effects of BBR might be partially mediated by the upregulation of lipolysis gene expressions and down-regulation of lipogenesis gene expressions through activation of the AMPK signaling pathway. 


\section{Oxidative stress}

The present study demonstrated a significant high level of MDA and a significant low level of TAC in diabetic control rats as compared with normal control. This effect is in agreement of Ilhan et al. (34) who reported that MDA reflects the degree of lipid peroxidation that plays an important role in diabetic pancreas damage. Also, Fukudome et al. (21) found that increased blood glucose and lipid levels in diabetic rats can mediate pancreatic beta-cell toxicity by generating ROS. Salem et al. (35) suggested that increased oxidative stress in diabetes contributes to the development of diabetic complications. Oxygen derived free radicals and reactive oxygen species interact with the lipid bilayer of the cell membrane resulting in lipid peroxidation.

The results of the present study showed that administration of $\mathrm{BBR}$ to diabetic rats decreases serum MDA level and increases TAC in comparison to diabetic control. The effect appeared at 2 weeks and approached the control level on the 4 weeks.

Our results are in the same line with other results obtained by other investigators as; Coskun et al. (36) found that BBR brought the increased MDA content in diabetic pancreas back to near the control one, which suggests that BBR had defensive nature of oxidative damage of cellular membranes and changes in the structure and function. Also, Zhu and Qian (37) reported that BBR decreases lipid peroxidation acting as a free radical scavenger, prevents accumulation of reactive oxygen species. Arulselvan and Subramanian (38) showed that relatively low content of antioxidant enzymes in pancreas may cause it more vulnerable to oxidative stress. However, BBR almost restored the pancreatic superoxide dismutase activity to near control level. Further, Abd El-Wahab et al. (39) found that BBR showed a significant reductive ability and radicals scavenging effects, especially on hydroxyl radicals.

\section{Kidney functions}

This study showed significant higher levels of blood urea and serum creatinine in diabetic control rats as compared with normal controls. The histopathological examination of the kidney of diabetic rats revealed vascular changes and vacuolar degeneration of renal tubules. In accordance with these results, Montero et al. (40) showed that oxidative stress in diabetic kidney is usually associated with tissue damage that interferes with proper organ function, causing an increase in urinary protein excretion and blood urea nitrogen. Heidland et al. (41) found that hyperglycemia enhances oxidative stress and directly affects mesangial cells to develop glomerulopathy. Also, Su et al. (42) revealed that increased oxidative stress play significant roles in the pathogenesis of diabetic nephropathy (DN).

The present study results showed BBR to diabetic rats decreases blood urea level and serum creatinin to the control level on the 4 weeks. Our histological results of the kidney confirm the blood results. This is in agreement with $\mathrm{Wu}$ et al. (43) who found that BBR ameliorates renal injury and proteinuria in rats with diabetes by inhibiting advanced glycation end products formation or accumulation and improving antioxidation. Moreover, $\mathrm{Xi}$ et al. (44) revealed that BBR treatment at the beginning of diabetes significantly 
delay the pathogenesis of DN and the renoprotective effect of BBR on renal inflammation DN partly depends on the inhibition of RhoA/ ROCK (rho kinase) signaling in diabetic rat kidneys and glomerular mesangial cells. The underlying molecular mechanism is closely related to its anti-oxidative stress effect.

In the present study we noticed significant increased levels of glucose, TC, TG, LDL, MDA, blood urea and serum creatinine and significant decreased levels of insulin, HDL and TAC after administration of berberine for 6 weeks when compared with normal control. The histological examination of the pancreas, liver and kidney confirm the blood results. These results may reflect a degree of toxicity of berberine or the receptors may become desensitized for long term usage.

\section{Sweet taste receptors}

In the current study BBR after $10 \%$ glucose application on the tongue of rats of group (7) decreased significantly the mean level of the rate of vagal nerve activity when compared with control and $10 \%$ glucose levels. The present data indicate that BBR may act through inhibition of sweet taste receptors.

In agreement with this result, Niijima (45) suggested that sweet taste stimulation with $5 \%$ glucose or $10 \%$ sucrose increased efferent activity of pancreatic branch of the vagus nerve. Jeong et al. (46) found that addition of bitter compounds to sucrose suppressed feeding behavior and attenuated nerve firings in sugar-activated gustatory receptor neurons. Moreover, Kessler et al. (47) showed that berberine had the ability to inhibit the sucrose receptor cells.

\section{Neural control of blood glucose}

Berberine interactions with parasympathetic and sympathetic nervous system have been studied in this work in attempt to detect its mechanism of action.

The present study showed that BBR increased significantly the mean level of the rate of vagal nerve activity in group (8) when compared with control level. While, pre-treated rats with atropine (cholinergic receptor blocker) decreased significantly the mean level of the rate of vagal nerve activity when compared with BBR level. These results indicate that BBR may exert its action by activation of vagus nerve. In accordance, Campfield et al. (48) demonstrated that a vagally mediated increase in plasma insulin concentrations resulted in a transient decrease in blood glucose that then induced spontaneous feeding in rats. Also, a study done by Pocai et al. (49) showed decreased hepatic glucose production involving parasympathetic circuits (vagal efferents).

Salehi and Filtz (50) hypothesized that some of berberine's effects are mediated through activation of M2 muscarinic cholinergic receptors. Moreover, Ji and Shen (51) added that BBR possesses inhibitory activity against acetyl choline estrase enzyme (AChE). Further, Abd El-Wahab et al. (39) reasoned that BBR binds AChE active site as it is acts as competitive inhibitor.

Berberine administration into animals of groups (9 and 10) increased significantly the mean level of the rate of sciatic sympathetic activity when compared with control level. While, pre- 
treated rats with prazocine ( $\alpha$-adrenergic receptor blocker) and propranolol ( $\beta$-adrenergic receptor blocker) decreased significantly the mean level of the rate of sciatic sympathetic nerve activity when compared with berberine level. These results suggest that berberine actions are mediated by activation of $\alpha$ and $\beta$ adrenoceptors.

In accordance, Olmez and Ilhan demonstrated that BBR appears to have relatively more affinity for post-synaptic alpha-1-adrenergic receptors than presynaptic alpha-2-adrenergic receptors. Zhao et al. [53] suggested that BBR has been found to interact with a binding site on the Beta-2-adrenergic receptor. Ji and Shen [51] added that berberine possesses inhibitory activity against MAO-A and MAO-B. Furthermore, Kulkarni and Dhir [54] found that acute administration of BBR

\section{REFERENCES}

\section{Mbanya J, Motala A, Sobngwi E, Assah F} and Enora S: Diabetes in sub-Saharan Africa. Lancet 375: 2254-2266, 2010.

\section{Adeleke S, Asani M, Belonwu R, Gwarzo G} and Farouk Z: Childhood diabetes mellitus in Kano, North West Nigeria. NIG J Med 19(2): 145-147, 2010.

3. Rother K: Diabetes treatment-bridging the divide. The New England Journal of Medicine 356 (15): 1499-501, 2007.

4. Marles R, Farnsworth N: Antidiabetic plants and their active constituents. Phytomedicine 2:137-89, 1995.

\section{Imanshahidi $M$ and Hosseinzadeh $\mathbf{H}$ :} Pharmacological and therapeutic effects at $5 \mathrm{mg} / \mathrm{kg}$ injections can raise neural norepinephrine by $31 \%$ in mice.

\section{Conclusions}

Berberine may have antidiabetic effect by which is evidenced by decreased glucose level, improvement of oxidative stress, dyslipidemia and kidney functions. Berberine may exert its action on glucose level through inhibition of sweet taste receptors. Also, It can act by activation of the cholinergic receptor, $\alpha$ and $\beta$ adrenoceptors. So, it may serve as a drug for the treatment of diabetes mellitus. However, BBR in long term use may cause a degree of toxicity or decreased sensitivity of the receptors. Thus, further studies are needed to examine different doses and time periods to clarify its mechanism of action and safety in longer periods.

of Berberis vulgaris and its active constituent, berberine. Phytother Res 22(8):999-1012, 2008.

6. Dong H, Wang N, Zhao L, Lu F: Berberine in the treatment of type 2 diabetes mellitus: a systemic review and meta-analysis. Evid Based Complement Alternat Med 2012:591654, 2012.

7. Yin J, Xing $\mathbf{H}$, Ye J.: Efficacy of berberine in patients with type 2 diabetes mellitus. Metabolism 57(5):712-7, 2008.

\section{Zhou L, Yang Y, Wang X, Liu S, Shang W,} Yuan G, Li F, Tang J, Chen M, Chen J. Berberine stimulates glucose transport through a mechanism distinct from insulin. Metabolism 56(3):405-12, 2007. 
9. Slaughter TN, Paige A, Spires D, Kojima N, Kyle PB, Garrett MR, Roman RJ, Williams JM. Characterization of the development of renal injury in Type-1 diabetic Dahl salt-sensitive rats. Am J Physiol Regul Integr Comp Physiol 305(7):R727-34, 2013.

\section{Saddala $\mathbf{R}$, Thopireddy L, Ganapathi $\mathbf{N}$ and} Kesireddy S: Regulation of cardiac oxidative stress and lipid peroxidation in streptozotocin-induced diabetic rats treated with aqueous extract of Pimpinella tirupatiensis tuberous root. Exp Toxicol Pathol 65 (1-2):15-9, 2013.

11. Olanlokun J: Protective influence of vitamine $\mathrm{E}$ on the antioxidant defense system in the whole blood and liver of normal and STZ-induced diabetic rats. Indian J Clin Biochem 23 (1): 62-66, 2008.

12. Zhang Q, Xiao X, Feng K, Wang T, Li W, YuanT, Sun X, Sun Q, Xiang H, Wang H (2011): Berberine Moderates Glucose and Lipid Metabolism through Multipathway Mechanism. Evid Based Complement Alternat Med 2011:1-10, 2011.

\section{Friedewald W T, Levy R I \& Frederickson}

D S: Estimation of plasma low-density lipoprotein cholesterol concentration without use of preparative ultracentrifugation. Clin Chem 18: 499 509, 1972.

14. Steffenas B: Influence of the oral cavity on insulin release in the rat. Am J Physiol 230: 1411-1415, 1976.
15. Singh B and Vaughan Williams E: A third class of anti-arrhythmic action: Effects on atrial and ventricular intracellular potentials and other pharmacological actions on cardiac muscle of MJ 1999 and AH-3474. Br J Pharmacol 39:675687,1970 .

16. Katona PG, Poitras JW, Barnett GO, Terry BS: Cardiac vagal efferent activity and heart period in the carotid sinus reflex. Am J Physiol 218 (4):1030-7, 1970.

17. Bolander $\mathbf{H}$ and Wahlström G: The interaction between atropine and some lipid-soluble barbiturates in rats. Acta Pharmacol Toxicol 54(2):81-5, 1984.

18. Dhasmana K, Villalon $\mathbf{C}, \mathbf{Z h u} \mathbf{Y}$ and Parmar S: The role of dopamine (D2), alpha and beta- adrenoceptor receptors in the decrease in gastrointestinal transit induce by dopamine releated drugs in rat. Pharmacol Res 27(4):335-47, 1993.

19. Mc Lead L: Pharmacological experiments on intact preparation. $2^{\text {nd }}$ edition, E.\& S. Livingstone, London, 1970, P40-45.

20. Riad A, Du J, Stiehl S, Westermann D, Mohr Z, Sobirey M and Doehner W: Low-dose treatment with atorvastatin leads to anti-oxidative and antiinflammatory effects in diabetes mellitus. Eur J Pharmacol 569: 204-211, 2007.

\section{Fukudome D, Matsuda M, Kawasaki T, Ago} Y and Matsuda T: The radical scavenger edaravone counteracts diabetes in multiple low-dose streptozotocintreated 
mice. Eur J Pharmacol 583: 164-169, 2008.

22. Ko B, Choi $\mathbf{S}$ and Park S: Insulin sensitizing and insulinotropic action of berberine from Cortidis rhizoma. Biol Pharm Bull 28: 1431-7, 2005.

23. Zhou J, Zhou S, Zhang K, Tang J, Guang L, Xu Y and Zhang L: Chronic effects of berberine on blood, liver glucolipid metabolism and liver PPARs expression in diabetic hyperlipidemic rats. Biol Pharm Bull 31: 1169-1176, 2008.

24. Xia X, Yan J, Shen Y, Tang K, Yin J, Zhang Y, Yang D, Liang $\mathrm{H}$, Ye J and Weng J: Berberine improves glucose metabolism in diabetic rats by inhibition of hepatic gluconeogenesis. PLoS One 6(2):e16556, 2011.

25. Viollet B, Mounier R, Leclerc J, Yazigi A, Foretz $M$ and Andreelli F: Targeting AMP-activated protein kinase as a novel therapeutic approach for the treatment of metabolic disorders. Diabetes Metab 33(6):395-402, 2007.

26. Chen $\mathbf{C}$, Zhang $\mathbf{Y}$ and Huang $\mathbf{C}$ : Berberine inhibits PTP1B activity and mimics insulin action. Biochem Biophys Res Commun 397(3):543-7, 2010.

27. Zhou L, Wang X, Shao L, Yang Y, Shang W, Yuan G, Jiang B, Li F, Tang J, Jing H, Chen M. Berberine acutely inhibits insulin secretion from beta-cells through 3',5'-cyclic adenosine 5'-monophosphate signaling pathway. Endocrinology 149(9):4510-8, 2008.
28. Al-masri I, Mohammad M and Tahaa M: Inhibition of dipeptidyl peptidase IV (DPP IV) is one of the mechanisms explaining the hypoglycemic effect of berberine. J Enzyme Inhib Med Chem 24(5):1061-6, 2009.

29. Gallwitz B: GLP-1 agonists and dipeptidylpeptidase IV inhibitors. Handb Exp Pharmacol 203:53-74, 2011.

30. Ginsberg H, Zhang $\mathbf{Y}$ and Hernandez A: Regulation of plasma triglycerides in insulin resistance and diabetes. Arch Med Res 36: 232-240, 2005.

31. Wasan $\mathbf{K}, \mathbf{N g} \mathbf{S}$, Wong $\mathbf{W}$ and Rodrigues B: Streptozotocin-and alloxan -induced diabetes modifies total plasma and lipoprotein lipid concentration and composition without altering Cholesteryl Ester Transfer Activity. Pharmacol Toxicol 83: 169-175, 1998.

32. Li GH, Wang DL, Hu YD, Pu P, Li DZ, Wang WD, Zhu B, Hao P, Wang J, Xu XQ, Wan JQ, Zhou YB, Chen ZT: Berberine inhibits acute radiation intestinal syndrome in human with abdomen radiotherapy. Med Oncol 27(3):919-25, 2010.

33. Cao S, Zhou Y, Xu P, Wang Y, Yan J, Bin W, Qiu F and Kang N : Berberine metabolites exhibit triglyceride-lowering effects via activation of AMP-activated protein kinase in Hep G2 cells. J Ethnopharmacol 149(2):576-82, 2013.

34. Ilhan N, Halifeoglu I and Ozercan H: Tissue malondialdehyde and adenosine 
triphosphatase level after experimental liver ischaemia-reperfusion damage. Cell Biochem Funct 19: 207-212, 2001.

\section{Salem M, Kholoussi S, Kholoussi $\mathbf{N}$ and} Fawzy R: Malondialdehyde and trace element levels in patients with type 2 diabetes mellitus archives of hellenic medicine 28(1):83-88, 2011.

\section{Coskun O, Kanter M, Korkmaz A and Oter}

S: Quercetin, a flavonoid antioxidant, prevents and protects streptozotocininduced oxidative stress and beta-cell damage in rat pancreas. Pharmacol Res 51: 117-123, 2005.

37. Zhu F and Qian C: Berberine chloride can ameliorate the spatial memory impairment and increase the expression of interleukin-1 beta and inducible nitric oxide synthase in the rat model of Alzheimer's disease. BMC Neurosci 7: 78, 2006.

38. Arulselvan $\mathbf{P}$ and Subramanian S: Beneficial effects of Murraya koenigii leaves on antioxidant defense system and ultra structural changes of pancreatic beta-cells in experimental diabetes in rats. Chem Biol Interact 165: 155-164, 2007.

39. Abd El-Wahab A, Ghareeb D, Sarhan E, Abu-Serie M and El Demellawy M: In vitro biological assessment of berberis vulgaris and its active constituent, berberine: antioxidants, antiacetylcholinesterase, anti-diabetic and anticancer effects. BMC Complementary and Alternative Medicine 13:218, 2013.
40. Montero A, Munger $\mathbf{K}$, Khan $\mathbf{R}$ and Valdivielso J: $F(2)$-isoprostanes mediate high glucose-induced TGF-beta synthesis and glomerular proteinuria in experimental type I diabetes. Kidney Int. 58: 1963-1972, 2000.

\section{Heidland A, Sebekova K and Schinzel R:} Advanced glycation end products and the progressive course of renal disease. Am J Kidney Dis 38:S100-106, 2001.

42. Su J, Zhang P, Zhang JJ, Qi XM, Wu YG, Shen JJ: Effects of total glucosides of paeony on oxidative stress in the kidney from diabetic rats. Phytomedicine 17(34):254-60, 2010.

43. Wu D, Wen W, Qi CL, Zhao RX, Lü JH, Zhong CY, Chen YY: Ameliorative effect of berberine on renal damage in rats with diabetes induced by high-fat diet and streptozotocin. Phytomedicine 19(89):712-8, 2012.

44. Xi X, Xiuting C, Lei C, Kaipeng H, Juan H, Shaogui W, Xiaoyan S, Peiqing $L$ and Heqing H: Berberine ameliorates experimental diabetes-induced renal inflammation and fibronectin by inhibiting the activation of RhoA/ROCK signaling. Mol Cell Endocrinol 381: 5665, 2013.

45. Niijima A: Effect of umami taste stimulations on vagal efferent activity in the rat. Brain Res Bull 27(3-4):393-6, 1991.

46. Jeong Y, Shim J, Yoon H, Kim C, Moon S and Montell C: An odorant-binding protein required for suppression of sweet 
taste by bitter chemicals. Neuron 79(4):725-37, 2013.

47. Kessler S, Vlimant $\mathbf{M}$ and Guerin P: The sugar meal of the African malaria mosquito Anopheles gambiae and how deterrent compounds interfere with it: a behavioural and neurophysiological study. J Exp Biol 216: 1292-1306, 2013.

48. Campfield L, Smith F and Rosenbaum M: Human hunger: is there a role for blood glucose dynamics? Appetite 18: 244, 1992.

49. Pocai A, Obici S, Schwartz G and Rossetti L: A brain-liver circuit regulates glucose homeostasis. Cell Metab 1:53-61, 2005.

50. Salehi $\mathbf{S}$ and Filtz T: Berberine possesses muscarinic agonist-like properties in cultured rodent cardiomyocytes. Pharmacol Res 63:335-340, 2011.

51. Ji $\mathbf{H}$ and Shen L: Molecular basis of inhibitory activities of berberine against pathogenic enzymes in Alzheimer's disease. ScientificWorld Journal. 2012: 823201-4, 2012.

52. Olmez $\mathbf{E}$ and Ilhan $\mathbf{M}$ : Evaluation of the alpha-adrenoceptor antagonistic action of berberine in isolated organs. Arzneimittelforschung 42(9):1095-7, 1992.

53. Zhao X, Nan Y, Xiao C, Zheng J, Zheng X, Wei $Y$ and Zhang Y: Screening the bioactive compounds in aqueous extract of Coptidis rhizoma which specifically bind to rabbit lung tissues beta2- adrenoceptor using an affinity chromatographic selection method. J Chromatogr B Analyt Technol Biomed Life Sci 878(22):2029-34, 2010.

54. Kulkarni S and Dhir A: On the mechanism of antidepressant-like action of berberine chloride. Eur J Pharmacol 589(1-3):16372, 2008. 


\section{الملخص العربى}

الهذف :تقييم تأثير بربيرين على مستوى السكر في الدم، الانسولين، صورة الدهون بالدم، ضغط الاكسدة وكذلك وظائف الكلى في ذكور الفئران البالغة المصابة بمرض السكري وكثف آليه عمله.

الطرق والمواد: استخدم ثمانون فارذكر بالغ و تم تقسيمه إلى عشر مجموعات .أجريت عليهم ثلاث تجارب .التجربة الاولى شملت المجموعة

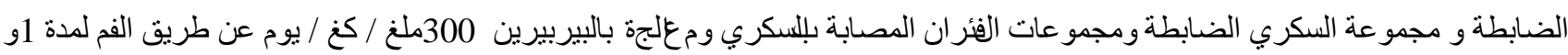

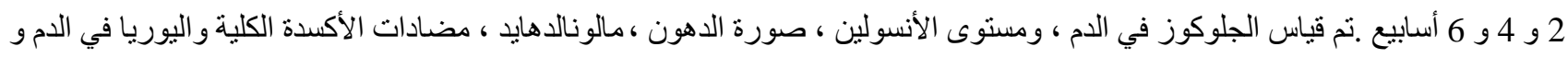

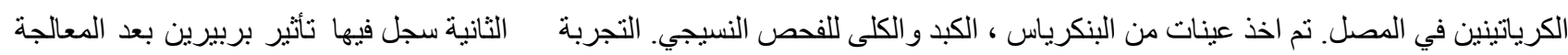

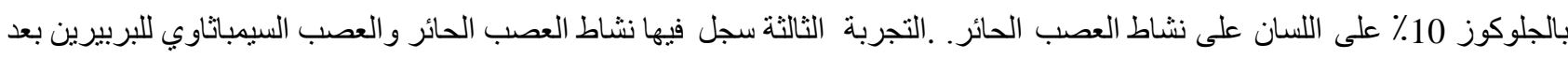

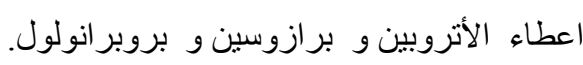
النتائج: أدى استخدام البربيرين الى نقص ذو دلالة احصائية في مستوى الجلوكوز ، الكوليستيرول الكلي ، الدهون الثلاثية ، كوليسترول الدهون

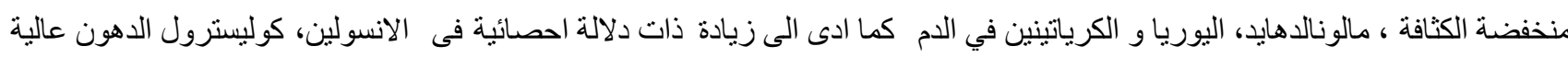

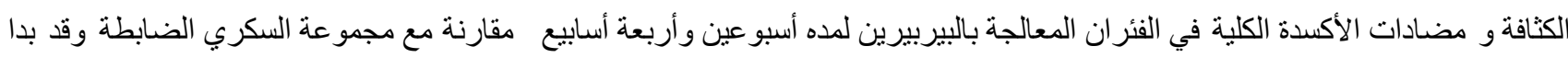

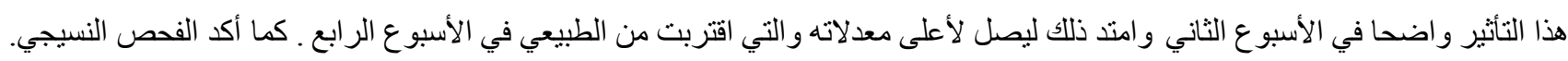

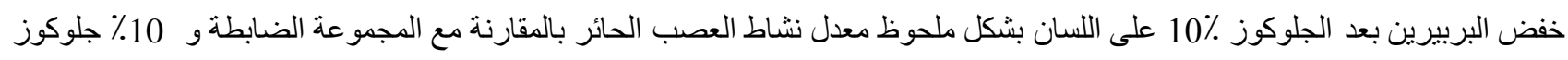

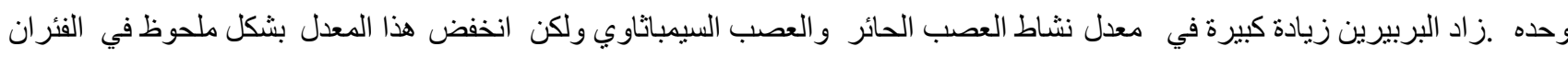

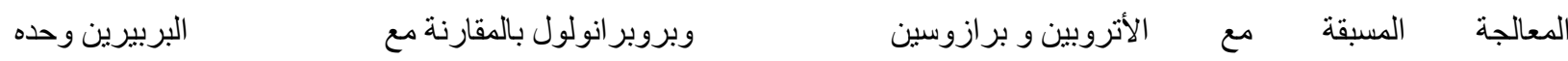
الاستخلاص : قد يكون لبربيرين نأثير مضاد لمرض السكرى. قد يعمل بربيرين على مستوى الجلوكوز عن طريق تثبيط مستقبلات الطعم الحلو .كما يمكن أن يعمل عن طريق تنشيط مستقبلات العصب البار اسمبثاوى و السمبثاوى (الفاوبيتا). 